\title{
CLAVES ICONOGRÁFICAS DEL UNIVERSO PICTÓRICO DE CURRO GONZÁLEZ
}

\section{ICONOGRAPHIC KEY POINTS OF CURRO GONZÁLEZ PICTORIAL UNIVERSE}

\author{
Clara Zamora Meca \\ Universidad Pablo de Olavide, España \\ czamora@upo.es
}

A Pedro Simón y Moreno de Vega

Este artículo se ha escrito con la intención de contribuir al esclarecimiento y a la sistematización de la producción pictórica del artista sevillano Curro González (Sevilla, 1960), cuyas aportaciones a la vida artística española y, sobre todo, hispalense han sido tan diversas como importantes. La finalidad más específica de este estudio es, pues, profundizar en el conocimiento del universo simbólico e iconográfico de su obra, llegando a conclusiones que clarifiquen su ingente producción creativa.

Palabras clave: Arte Contemporáneo, Arte Andaluz, Pintura Contemporánea, Curro González

This article has been written with the intention of contributing to the clarification and systematization of pictorial production Sevillian artist Curro Gonzalez (Seville,1960), whose contributions to the Spanish artistic life and, above all, Seville have been as diverse as important. The specific purpose of this study is therefore to deepen the knowledge of the symbolic and iconographic universe Curro González's work, reaching conclusions that clarify their enormous creative output.

Keywords: Contemporary Art, Andalusian Art, Contemporary Paintig, Curro González

La figura artística de Curro González representa una personalidad clave en la generación de jóvenes artistas que apostaron por los nuevos postulados de modernidad en la Sevilla de los años ochenta del pasado siglo XX. Este personaje se caracteriza por una honda inquietud, una brillante acidez y una gran preocupación por los distintos problemas que le rodean. Su espíritu crítico y renovador se plasma en una cuantiosa producción artística perfectamente estructurada. 
El arte para Curro González es el sustituto del sueño en el estado de vigilia. Es el lenguaje que pretende constatar el curso del tiempo y que puede hacer que la mente vague como cuando duerme. Es un revulsivo personal, no pretende complacer al espectador, su arte no responde a la voluntad de hacer algo bello. El artista trata de inquietar, de provocar un diálogo con uno mismo proponiendo él las claves para iniciarlo. Hombre ácido y reaccionario, este artista conoce la versatilidad de sus demonios personales. Sus fantasmas particulares tienen, a través de sus pinturas, un lugar dónde habitar liberando al autor de un inevitable desasosiego interno.

La obra de Curro González requiere para su comprensión cierto conocimiento de las claves iconográficas que subyacen en ellas. Los cuadros de este artista no basta con mirarlos, hay que conectar con ellos. Es necesario ralentizar su lectura, pues sus pinturas despliegan diferentes e interesantes narrativas. Su progresión ha sido evidente, demostrando cada vez más que es un artista reflexivo con un carácter compulsivo y obsesivo, como revela a través de la reiteración de temas, que explota hasta agotarlos.

A través de unas etapas muy marcadas y de una extensa producción artística constituida en su mayoría por dibujo y pintura, (siendo la escultura y la animación menos frecuente), Curro González nos desvela su mundo interior, sus anhelos, sus miedos, su juicio crítico y mordaz sobre la realidad que le ha tocado vivir, demostrando una capacidad extraordinaria para ironizar con sus propias manías. Artista con una destacada competencia para hacer de cronista, deja con su producción artística una herencia a considerar sobre la evolución de la humanidad en el tránsito de milenio, como ya hicieran sus admirados predecesores Brueghel o Hogarth, hombres todos dotados de brillante inteligencia y que supieron aunar su virtuosismo artístico con el ingenio, el humor ácido y una capacidad analítica envidiable. Son artistas que entienden que el arte posee una función moral: la denuncia a través de la sátira.

Las claves iconográficas que subyacen y clarifican la producción pictórica de Curro González son las siguientes:

\section{LA MEMORIA}

La fragilidad y el carácter perecedero de la memoria configuran uno de los temas principales en la producción de Curro González. Aunque es en la serie $\mathrm{Al}$ Margen de Giordano Bruno (1997) donde la aborda de lleno, ha estado presente de alguna manera en el trasfondo de gran parte de su obra como una especie de obsesión constante. El artista demuestra así la angustia que le produce la pérdida de elementos y detalles de algún episodio concreto de su vida. 
Nuestro "disco duro" tiene una capacidad infinita de memoria. Sin embargo, lo que no se usa se queda en el olvido ${ }^{1}$. Esta es la cuestión que provoca la inquietud de Curro González. Él es consciente de que la memoria es algo que se desarrolla, que puede mejorarse con las técnicas adecuadas y que supone una herramienta importante y fundamental para la relación de conocimientos. Su obsesión es conservar en la memoria una imagen exacta de lo que se ve, de ahí viene también en parte su admiración por figuras como Bruegel o Hogarth, artistas con una capacidad de retención visual extraordinaria, gracias a la cual pudieron reflejar escenas llenas de detalles del mundo que les rodeaba y que han quedado como un valioso testimonio documental.

Los últimos años de la década de los noventa, Curro González incorporó a su obra la preocupación por la memoria y su relación con la filosofía hermética de Giordano Bruno (paradigma de respuesta-interpretación marginal y heterodoxa) o el lenguaje y la viabilidad de la hermenéutica. En 1997 presentó el resultado de estas reflexiones en varias exposiciones ${ }^{2}$ (Figura 1).

\section{LA PERCEPCIÓN}

La percepción como laboratorio de los sentidos, como máquina codificadora de lenguajes es algo que interesa a Curro González a lo largo de toda su carrera, estando presente en toda su producción de una forma más o menos evidente. El proceso de la percepción es de carácter deductivo y constructivo ${ }^{3}$, generando una representación interna de lo que sucede en el exterior a modo de hipótesis. Es en este punto donde conecta la percepción con la memoria.

De todas, la percepción a través de la vista es la que más interesa a Curro González, formando parte de la preocupación general que caracteriza toda su trayectoria. El ojo es vértice de la construcción mental que penetra hacia el interior de la mente. La retina se prolonga como un espacio infinito originando una red donde se entrelazan infinitos nudos. Sus obras son como un ojo crítico en su experiencia visual capaz de revisar el mundo exterior, espacios obsesivos realizados a través de asociaciones múltiples. A Curro González le interesan los estudios clásicos sobre la percepción: los del historiador británico Ernst Gombrich y,

${ }^{1}$ Es un mito creer que la edad disminuye la memoria; lo que disminuye es el uso del cerebro. Nos hacemos perezosos mentales. Dejamos de ejercitar el músculo y perdemos el interés por aprender y recordar cosas nuevas.

${ }^{2}$ Soñando Babel (Galería Joan Prats, Barcelona), Al margen de Giordano Bruno (Galería Tomás March, Valencia; Museo Cruz Herrera), Laberinto de fortuna (Galería Xavier Fiol, Palma de Mallorca), Un palacio sin puertas (Galería Windsor K., Bilbao).

${ }^{3}$ Tal como lo propuso el médico y físico alemán Hermann von Helmholtz. 
sobre todo, los que aportó Rudolf Arnheim ${ }^{4}$, quien argumentó la imposibilidad de la existencia de inteligencia sin la percepción. El lenguaje solamente sirve para nombrar lo que ya ha sido escuchado, visto o pensado. En este sentido, el medio del lenguaje puede paralizar la creación intuitiva y los sentimientos ${ }^{5}$. Los juegos y las reglas de la perspectiva y todo lo relacionado con la representación espacial están imbricados en sus dibujos y pinturas desde aquella Escalera que pintara en 1985 hasta sus obras más recientes. Curro González encuentra un mundo fascinante en las deformaciones y las lecturas aberrantes que están contenidas dentro de los diferentes juegos de perspectivas que se pueden realizar.

La metodología nueva pasa por la utilización del ordenador para componer los cuadros. Mediante esta tecnología, el artista se plantea un nuevo proceso manual y cognitivo, siendo su aplicación práctica únicamente la de componer y estructurar con los parámetros conocidos como fondo/figura, como una "batidora" más rápida. La vista, la mirada, sus cualidades y sus limitaciones, llaman poderosamente la atención de Curro González. El año 2003 bajo el título El Intruso trató el tema del testigo ocular, la violación visual, el pintor-espectador y la mirada en la historia del arte. El artista denuncia la obstinación social por buscar la nitidez en la visión como una afición algo pornográfica. La imagen no se hará más real porque se presente con toda su crudeza. Nuestra visión se apoya de manera inevitable en el inconsciente (Figura 2).

\section{IRONÍA, SARCASMO, HUMOR}

A partir de los últimos años de la década de los $80 \mathrm{y}$, sobre todo, durante los años 90, el artista empezó a sentir la necesidad de mantener una distancia con la obra que le permitiera crear piezas que no estuvieran determinadas por sentimientos o intereses personales. Lógicamente, al hacer un análisis introspectivo implicaba sus afectos y pesares personales. Para conseguir distanciarse de ellos, comenzó a utilizar unos instrumentos que se convertirían en fundamentales e imprescindibles en la evolución de su trayectoria. Las herramientas que utilizó González para ello fueron el filtro de la ironía, el sarcasmo y el sentido del humor, recursos que demuestran un laborioso ingenio por parte del artista.

Surge entonces el conflicto de los lenguajes eruditos que, independientemente de la disciplina de la que se trate, requieren de un observador-espectador que sepa

${ }^{4}$ Rudolf Arnheim (1904 -2007), psicólogo y filósofo nacido en Berlín, dedicó su vida profesional a la investigación de estas dos cuestiones: ¿De qué modo es importante la percepción y de qué modo está ligada al pensamiento? y ¿No es el lenguaje el legado de una experiencia pasada, pensada, vista y escuchada, pero al que le falta inmediatez para explicar los estímulos directos que percibimos?.

5 ARNHEIM, R.: Arte y Percepción Visual. Psicología del ojo creador. Madrid, Alianza, 1979. Edición original de 1954. 
leer su lucidez. Si ya el uso cotidiano del lenguaje oral necesita que se note que el tono usado es efectivamente irónico, la obra pictórica requiere -pues no hay más medios- que este se entienda por sí mismo, sin otra posible explicación que la propia imagen. La ironía está inserta en nuestra compresión del mundo y puede ser una interesante clave de lectura frente a la realización artística contemporánea, observándola como una re-edición constante en busca de nuevas evidencias y escarbando nuevos síntomas propios del mundo expuesto que pudieran parecer a disposición total, pero luego se nos aparecen las parcialidades que nos sujetan a conocimientos previos, códigos culturales, sociales, políticos, económicos que van articulando finas capas discursivas.

Curro González mira a los grandes maestros de la pintura que emplearon este género y los reinterpreta. Valga como ejemplo la inclusión de la obra de Brueghel El pintor y el aficionado (hacia 1565) en la obra de González El amargo triunfo de la pintura, pintado en 1998. El humor se convierte en un instrumento de análisis crítico. Escribió Hegel que cuando una época ha llegado a su fin, todo lo sagrado se convierte en comedia ${ }^{6}$. Esto toma sentido de nuevo en el cambio de milenio, pues, como afirma el filósofo Juan Antonio Rodríguez Tous, cada fin de época ha tenido en los humoristas sus mejores intérpretes: Brueghel se rió de la quiebra del orden medieval, Hogarth lo hizo de la modernidad ilustrada y Daumier ironizó a la burguesía política. Todas ellas son figuras referenciales para Curro González (Figura 3).

\section{EL AUTORRETRATO Y LA CARICATURA}

El autorretrato es un género que alcanzó su esplendor en el Renacimiento, representando la autoafirmación del artista en el nuevo estado que entonces alcanzara en la consideración de su profesión, de su nivel intelectual y de su lugar en la escala social. A partir del siglo XX, los artistas otorgaron mayor importancia a la identidad metafórica del retratado. La caricatura es un retrato que exagera o distorsiona la apariencia física de una persona o varias y, en ocasiones, un estrato de la sociedad reconocible para crear un parecido fácilmente identificable y, generalmente, humorístico. Su técnica usual se basa en recoger los rasgos más marcados de una persona y exagerarlos o simplificarlos para causar comicidad o para representar un defecto moral a través de la deformación de los rasgos. El escritor y crítico Charles Baudelaire escribió una serie de artículos en los que distinguía claramente dos tipos de caricaturas. La primera establecía vínculos con lo grotesco, que es el modo clásico de exagerar los rostros y cuerpos hasta conseguir ser un personaje más de un bestiario clásico o medieval, como es el caso de un fauno o una gárgola. El otro tipo respondía a la caricatura moderna cuyo

${ }^{6}$ HEGEl, Georg Wilhelm Friedrich: Fenomenología del Espíritu, trad. W. Roces, FCE, Buenos Aires, reimpr. 1992. 
estilo se ha conservado hasta la actualidad. La caricatura es sobre todo un estilo mordaz y crítico propio de la modernidad, que ha estado ligada a cuestiones políticas y sociales. Dos artistas relevantes en este campo fueron Honoré Daumier y Toulouse Lautrec.

Los autorretratos son una de las preocupaciones centrales que subyacen en la obra de Curro González, suponiendo un cuestionamiento obsesivo de su propia identidad. Los rostros aparecen como una manifestación de los límites y la profundidad de la apariencia. Al artista no le interesa ninguna interpretación de tipo psicológico. Para él la representación del yo es como un campo de batalla, un terreno para la investigación, para la transformación y el análisis. Con la interpretación de lo demás, Curro González comienza a formar la primera visión de sí mismo; debemos, pues, entender sus autorretratos como un medio para expresar su relación y sus posibles afinidades con un medio más amplio. Mediante su creación, el artista traza un juego de doble identidad que le permite realizar un análisis externo e interno de los asuntos cuyo interés trasciende el campo de lo personal, objetivando ese yo. Los autorretratos de Curro González hay que entenderlos como conflictos naturales entre el yo como individuo y la sociedad: "camino por el pasillo como por las venas"?.

Es importante tener presente que esta profusión de autorretratos y caricaturas que aparecen en la obra de curro González hay que interpretarlas siempre en clave humorística. El artista se presenta como mero artilugio o juguete, se convierte en una especie de idea sin identidad específica, de modo que puede adoptar cualquiera según le interese, como un actor que va cambiando de papel según la película. Para Rodríguez Tous "el juego proteico de los autorretratos en la obra de Curro González es también una burla del culto posmoderno a un Yo flexible y poliédrico. Es un modo de ocultarse mientras se avanza; larvatus prodeo"8. No hay que olvidar que la risa ha sido siempre una terapia libre contra el yo (Figura 4).

\section{LA CULTURA DE MASAS EN LA SOCIEDAD DE CONSUMO}

El hombre contemporáneo, sometido e impregnado por la cultura audiovisual y sus sistemas de producción, da sentido al origen massmediático predominado por signos de seducción y de fantasía perenne. Es un hombre (como en el universo de 'Matrix') cada vez más alejado de la realidad y con un alto grado de perturbación simbólica y perceptiva. Y es que la función primordial de las industrias culturales o del entretenimiento y de la máquina imparable de los medios de masas es mantener a grandes mayorías alejadas de sí mismas asumiendo actitudes

${ }^{7}$ GONZÁLEZ, Curro: Doble Dirección 1988-1994, en catálogo Doble Dirección, Sevilla, Fundación Luis Cernuda, Diputación de Sevilla, 1994, p. 63.

${ }^{8}$ Rodríguez Tous, Juan Antonio: El artista voyeur, catálogo Estudio de Noche, Centro de Arte Contemporáneo de Málaga, 2008, p.21. 
complacientes y ecuánimes ante la realidad (decía Sócrates que un ser que no se piensa a sí mismo, no merece existir). Este fenómeno sustituye el imaginario colectivo, el reconocimiento y la representación de símbolos y arquetipos que han contribuido a edificar las bases de la civilización, de la historia, de la filosofía y del conocimiento por estereotipos provenientes de la 'cultura de masas".

El fervor por el artificio y su conversión en lo natural ha traspasado los límites de la personalidad y la individualidad para convertirse en una especie de hilo conductor que permite entender nuestro mundo contemporáneo. Una gran parte de esta nueva realidad se conforma a imagen y semejanza de la industria de Hollywood: el cine americano, junto con su modelo de felicidad empaquetado en el happy end ${ }^{10}$. En algunas obras de los últimos noventa, Curro González ya asume estos conceptos que le provocan un profundo rechazo y preocupación como temática dentro de su producción artística. Obras como Gaslighter's Nightmare I y II proponen una reflexión sobre la vacuidad del desfile narcisista que se inició a finales del siglo XX. El bosque cómico reflexiona también en diferentes consecuencias de esta sociedad de consumo provocada por la cultura de los mass media.

La sociedad de consumo, su consecuente manifestación de la cultura entendida como espectáculo así como la artificial y estereotipada alegría de los nuevos rituales de diversión popular (cuya más genuina manifestación serían los denominados "parques temáticos" construidos frecuentemente a imagen y semejanza del modelo original de Disneylandia) evidencian la relación que todo ello guarda con la influencia o contaminación que ejerce la civilización estadounidense sobre la visión contemporánea del mundo, en tanto que principal impulsora y promotora de los ideales y las formas que ofician en esta liturgia del capitalismo triunfante. En muestras como Party Final (2002) o Deja que el Futuro Pase de Largo (2003), el autor vierte todos estos contenidos teñidos por esa máscara que le caracteriza. El filtro de la ironía y el sentido del humor disfrazan una profunda pesadumbre y desencanto ante los nuevos mecanismos que mueven esa cultura actual de usar y tirar. Las fronteras entre entretenimiento, educación y comercialización colapsan ante la omnipotencia total de Disney y su alcance en las diversas esferas de la vida diaria. La extensión de su imperio revela tanto la sagacidad de sus prácticas comerciales como el ojo certero para brindar sueños y productos a través de las formas de la cultura (Figura 5).

${ }^{9}$ BARTHES, Roland: Mitologías, México, Siglo XXI, 1980.

${ }^{10}$ RIVIÈRE, Margarita: Lo Cursi y el Poder de la Moda, Madrid, Espasa, 1992, p. 131. 


\section{VANITAS}

La idea de la brevedad de la vida, de la fugacidad del tiempo, la certeza de la muerte, el menosprecio del mundo, la vida como una peregrinación, el desprecio de las riquezas o la melancolía son algunos de los mensajes que transmite y constituye la vanitas. Todo ellos a través de un sombrío punto de vista sobre el mundo. Se trata de una exaltación de la mirada como vehículo para el conocimiento y el saber, ya que el discurso de la vanitas despliega una serie de metáforas en la que la visualidad desempeña un papel protagonista. La mirada que es, en definitiva, el instrumento del desengaño ${ }^{11}$.

La vanitas que presenta Curro González en sus obras es siempre una vanitas laica, ya que en su adolescencia perdió su fe católica desengañado profundamente. El artista es consciente de que cielo e infierno son los mitos que cohesionan el mundo en el que vivimos. A pesar de no creer en ellos, estos conceptos ya han anidado en su mente desde su infancia en un colegio religioso y el artista articula inevitablemente en torno a ellos un sinfín de metáforas que dan forma a sus pensamientos y, en consecuencia, a su producción artística.

Hay que aludir también a otro concepto relacionado de alguna manera con el anterior y que también está presente en la obra de Curro González. Me refiero a El Theatrum mundi o Teatro Mundo, un tópico literario que explica que la sociedad es como un teatro. Mediante esta metáfora, explicaba Platón ${ }^{12}$ que los humanos son y funcionan como marionetas, pero también la propia religión cristiana afirma que el mundo es un teatro, cuyo único espectador es Dios desde el cielo. Otros autores como Balzac, Baudelaire o incluso Freud también trataron este concepto.

En 1993, Curro González realizó la serie Retablo, en la que hizo una crítica a la divinización de los valores de finales de siglo XX, esa "cultura de supermercado" que tanto ha desarrollado el artista en su obra, siempre a través del filtro de la ironía. En las obras de esta serie, los santos son personajes vulgares, corrientes, que observan plácidamente, sonríen, aparecen como anestesiados ante lo que ven, sin cuestionarse nada. González denuncia la imitación, el mimetismo, el artificio, lo redundante, el efectismo, el cliché de una realidad ficticia, el bloqueo de lo creativo, la indiferencia y la pasividad. Los retablos barrocos de las iglesias sevillanas anclados en la memoria de Curro González desde su infancia son el origen de la concepción de esta serie. También es una referencia, desde su infancia, la fachada del Ayuntamiento de Sevilla, primer edificio público renacentista de la ciudad (1526) (Figura 6).

${ }^{11}$ VIVES-FERRÁNDIZ SÁNCHEZ, Luis: Vanitas. Retórica visual de la mirada, Madrid, Encuentro, 2011.

12 Véase: El mito de la Caverna o Leyes. 
A modo de conclusión y de manera general, estas claves iconográficas ponen de manifiesto que el artista, a pesar de desenvolverse en una época sin referentes definidos, con cambios continuos de paradigmas y repleta de modas tan superficiales como efímeras, ha sabido mantener una línea de actuación fiel a sus principios y a sus bases estéticas, evolucionando continuamente y dejando una obra cada vez más seria y contundente. Ello le ha permitido soslayar todo lo circunstancial y transitorio para decantarse definitivamente por una producción dedicada a la investigación de los más ocultos sentimientos humanos. Su obra debe situarse entre la de los artistas plásticos que apostaron por desarrollar su actividad dentro de unos planteamientos creativos personales, no adscritos a ninguna corriente o postulado artístico específico. Su universo iconográfico hay que relacionarlo con el pensamiento ilustrado, esto es, una concepción racionalista y empírica del mundo, de la cual deriva su voluntad de descripción y crítica analítica.

Fecha de recepción: 15 de septiembre de 2014

Fecha de aceptación: 28 de noviembre de 2014

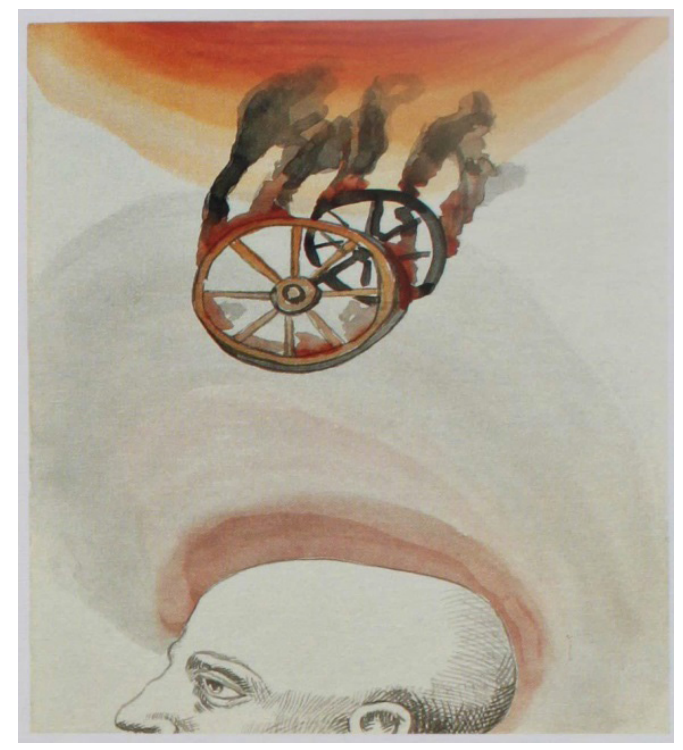

Figura 1.

El tiempo perdido, 1997

Serie "Al margen de Giordano Bruno"

Técnica mixta/papel 44'5x31'5 cm. 


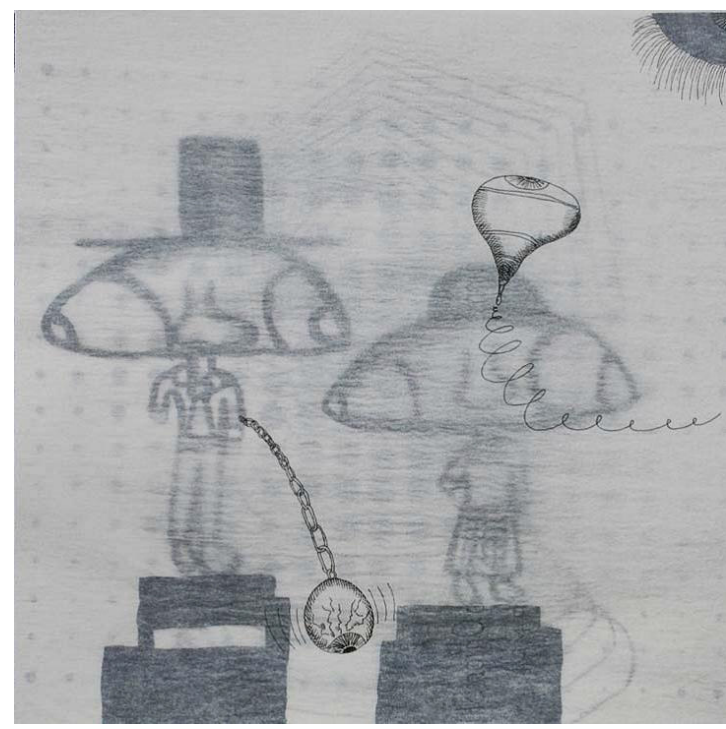

Figura 2.

Los problemas de la familia Ojo, 1999. Serie "Contradanza"

Técnica mixta/papel 39'5x39'5 cm.

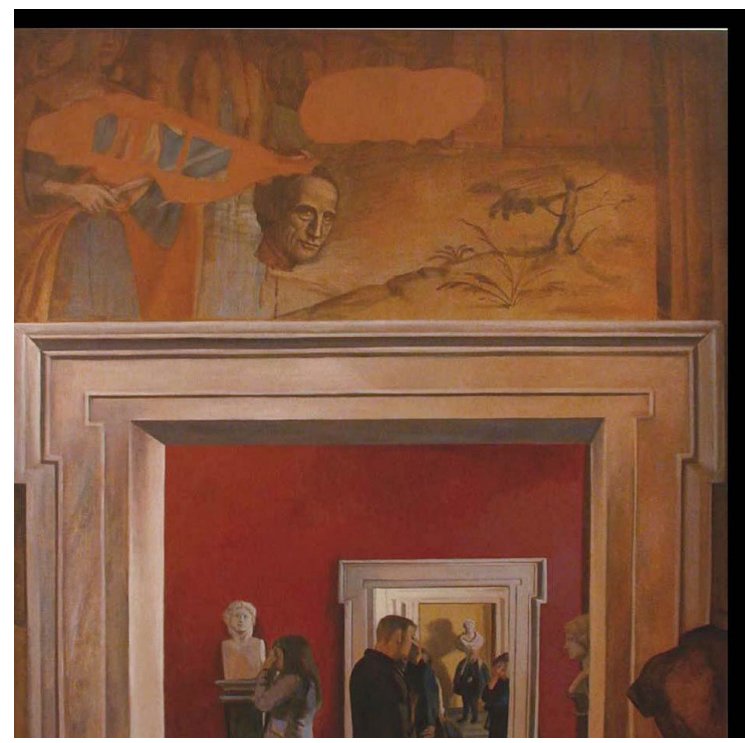

Figura 3.

Deslumbrados, 2004

Técnica mixta/telal 200x200 cm. 
Figura 4. Castor, 2008

Técnica mixta/escultura $35 \times 55 \times 25 \mathrm{~cm}$.aprox.

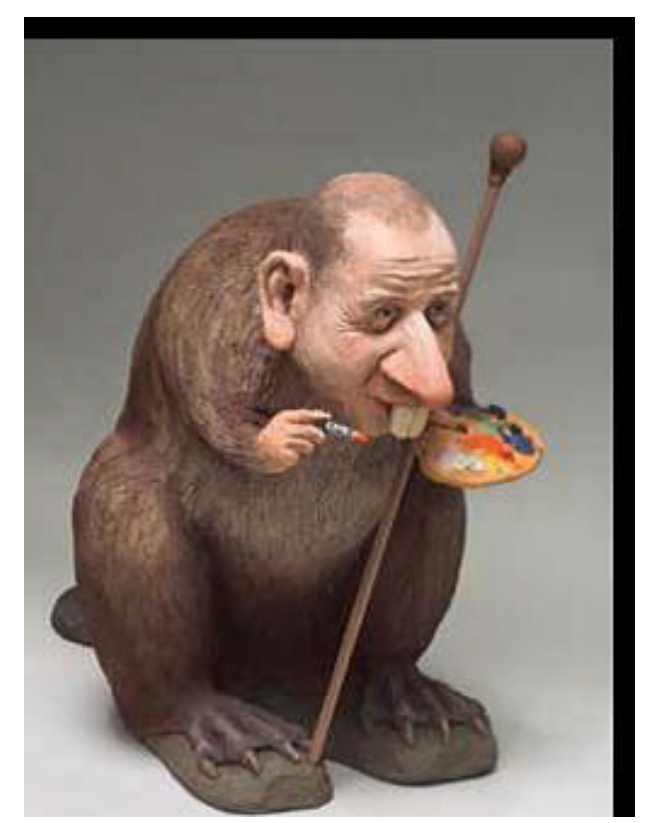

Figura 5.

Donald Top, 2003

Técnica óleo/tela 150x150 cm.

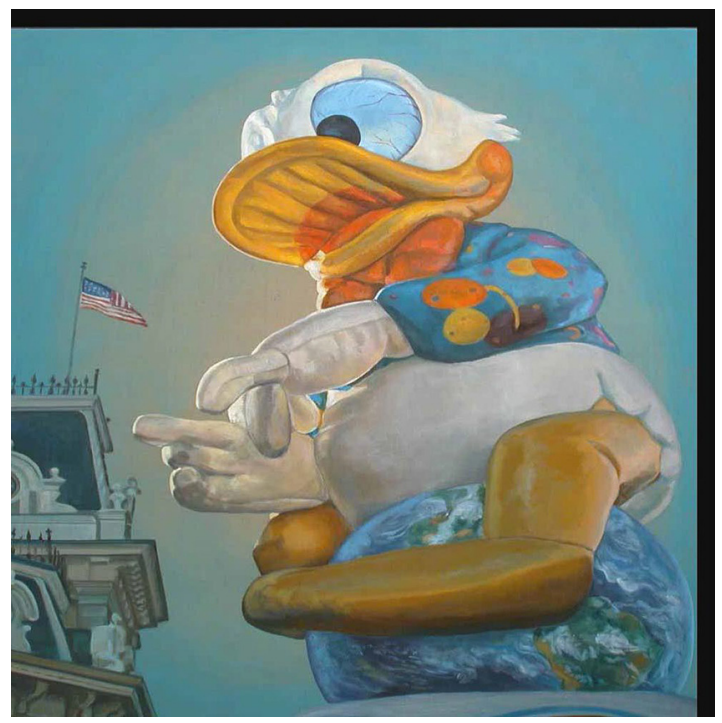




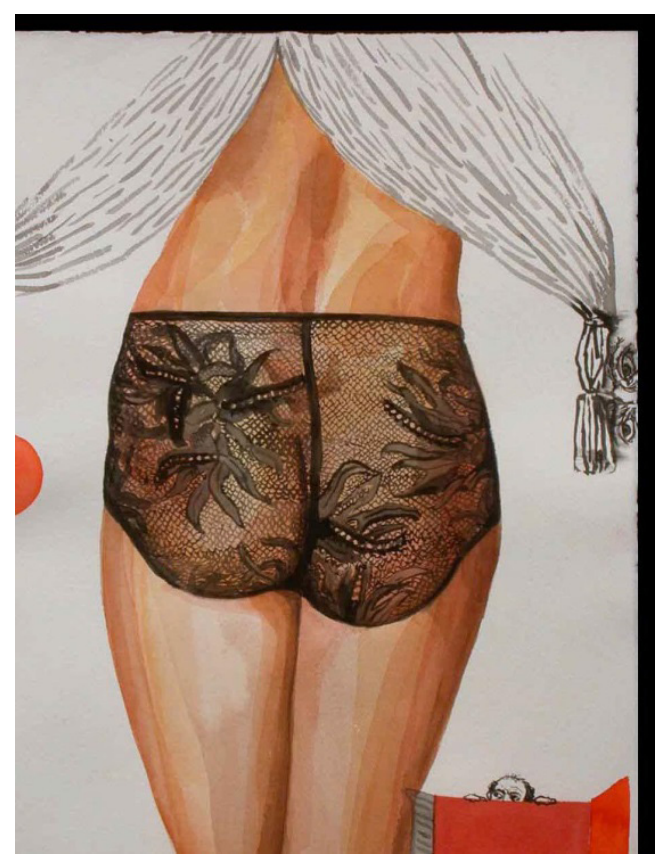

Figura 6.

Vanitas, 2003

Técnica acuarela/papel $38 \times 28^{\prime} 5 \mathrm{~cm}$. 